\title{
Norm Development in outsourcing relationships
}

\section{Thomas Kern}

Dept. of Info. \& Decision Sciences

Rotterdam School of Management

Erasmus University Rotterdam

Postbus 1738

3000 DR Rotterdam

The Netherlands

Tel: +31 (0)10 4081908

E-mail:tkern@fbk.eur.nl

Keith Blois

Templeton College,

University of Oxford.

Oxford, OX1 $5 \mathrm{NY}$.

Tel: $\quad 01865-422700$

E-mail:keith.blois@sbs.ox.ac.uk

\begin{abstract}
This paper considers the role of norms within networks by describing how BP Exploration out-sourced its information technology (IT) function - a major business activity. This outsourcing venture led to an attempt to create a network rather than to use a "market" form of organization. However, in some ways this attempt was found to have failed. It is suggested here that central to the effective failure of the consortium as an outsourcing arrangement was the issue of "norms".
\end{abstract}

\section{Introduction}

This paper will describe a decision by BP Exploration (BPX) to out-source a major business activity - its information technology (IT) function - a function that was subject to rapid technological change and where there were multiple technological dimensions. Unusually this outsourcing decision led to an initial attempt to create a network rather than to use a "market" form of organization. However, in some ways this attempt was found to have failed and the outsourcing deal was subsequently reorganised using a "hierarchical" form of organization. IT outsourcing is the practice of contracting out or selling the organization's IT assets, people and/or activities to a third party supplier, who in exchange provides and manages the assets and services for monetary returns over an agreed time period (Loh \& Venkatraman 1992; Lacity \& Hirschheim 1993).

The paper describes the history of this process and suggests that a crucial factor leading to the failure of the network approach was the failure to establish norms of behaviour.

\section{Research Approach}

The material in this paper was collected through the use of an in-depth longitudinal case research method. This research method was seen to be consistent with the focus of the research on the norms in an outsourcing relationship - which in essence was to understand 
'how' norms operated in outsourcing relationships and 'what' they encompassed. Case research in such a context is particularly appropriate for exploratory research of this nature (Pettigrew 1990; Walsham 1993). The approach making it possible to investigate "sticky, practice-based problems [such as outsourcing relationship practice] where the experiences of actors are important and the context of action is critical" (Benbasat, Goldstein and Mead 1987, p.370).

The research study's design was influenced by three main points. First, the BPX - multiple supplier outsourcing contract, signed in 1993 was investigated because it involved an innovative deal that focused on developing alliance type relationships between a group of suppliers and a customer. Second, with this outsourcing relationship it was possible to obtain multiple insights into how norms are formed and operate because it involved many stakeholders including: users/benefactors of the outsourcing service; client relationship managers; vendors' account management teams; and, the vendors' technical service groups. Thirdly, access to senior managers, from both customer and suppliers, in charge of a single and multiple accounts within the relationship was possible. This made it feasible to obtain a comprehensive view of the development of the relationship.

\section{Data Collection and Analysis}

The data collection was undertaken between December 1996 and June 1997 through interviews and reviews of various documentation. The documentation included internal documents such as: bid documentation; transition status reports; infrastructure change requests; memos; contract extracts concerning particular service infrastructures such as network maintenance, telecomms, and computing support; annual reviews; other reports such as strategy documents and change proposals; a number of presentations by senior managers at BPX; and, numerous organisational charts from the initial outset in 1994 to relational changes in 1997. In addition secondary literature was collected including: a number of journal articles covering outsourcing, process management and organisational changes at British Petroleum; existing published case studies by Harvard and the European Case Clearing House; numerous current and backdated newspaper articles accessed through various CD-ROM databases; and, various trade press articles from Computing, InformationWeek, ComputerWeekly, CIO, and Management Today.

Interviews lasting between 60 to 180 minutes were conducted with managers from BPX and the vendor companies. These were with IT managers, IT Director, Account Managers, Senior Contract Manager, Commercial Development Manager, Deputy Head of IT, Partner Resource Managers, General Manager of IT, Head of IT, Head of Business Information and Process International Systems Programme and Vendor Account Executive. The interviews were conducted using open-ended questions, which were informed by the literature on IT outsourcing, norms, interorganisational relationships, behaviour in relationships and relationship management in outsourcing. The semi-structured interview protocol ${ }^{148}$ was designed to elicit data about the outsourcing situation, relationship practice, relationship behaviours. To encourage open discussions all interviewees were assured of anonymity when they requested it. The interviews were transcribed and verified with the relevant respondents. By applying the precepts of intentional analysis to the transcripts (Sanders 1982) a higher level of abstraction and interpretation was achieved. Additionally by using the supporting secondary documentation a comprehensive case history was constructed.

${ }^{148}$ A copy of the actual interview protocol can be obtained from the authors upon request. 
These procedures made it possible to develop a qualitative, interpretative approach to the construction of the case study described in the next section (cf. Walsham 1995).

\section{The Case}

Background British Petroleum's growth and diversification had, by the 1980's, resulted in a very large, inflexible, people intensive and hierarchically structured organisation. Indeed in 1992, as a direct consequence of earlier rash investments BP spiralled into a loss (Mortished 1998). Changes to the organisation had therefore become necessary, and

"In 1990 BP announced a fundamental change of its corporate structure, known as Project 1990. The main aims were to reduce organisational complexity, re-shape the central organisation and reduce its cost, reposition BP for 1990s." (Jones 1991, p. 379)

"Project 1990" involved a renewed focus on BP's core competencies. So in those areas where third party organisations were believed to be superior, BP sought to gain access to their expertise and knowledge by forming alliances through, for example, outsourcing.

BPX is BP's second largest and most capital intensive division that is responsible for exploration and production operations in 16 countries. In line with the corporate wide changes in the 1990s, BPX was to become more autonomous and decided to flatten its organisation and replace its existing management structure, with a new global management team (Cross et al. 1997). Key to these changes was the use of information technology to facilitate communications. IT was also seen to be an essential ingredient for improving overall productivity. In addition, BPX's IT function played a critical role in supporting the exploration and production operations.

In 1989 BPX's IT infrastructure was primarily based on large VMS mainframe systems with approximately 1400 personnel. To improve operations BPX decided in late 1989 to embark on an extensive IT change. The aim was to cut IT costs while preserving the IT service to the business. The routes selected for achieving these changes involved (Currie and Willcocks 1997):

- eliminating human resources duplication;

- making large reductions in staff numbers;

- forming single 'centres of excellence' to provide support for all sites;

- rationalising applications; and

- IT outsourcing.

In the three years following 1989, BPX consolidated seven of its IT departments into one global department, standardised a range of systems across BPX, and closed down all but two data-centres. This led to costs falling from $\$ 360$ million to $\$ 170$ million by 1992 . In the same period computing power increased and new technologies were implemented. The prime responsibility of the remaining people was now the architecture, planning and overseeing of the infrastructure and the applications development budget was reduced by 69\% from 1989 to 1995 (Cross et al. 1997).

In 1993 in pursuit of further cost savings BPX looked towards large-scale IT outsourcing. Outsourcing was to contribute financially towards the restructuring project and led to the "rationalisation of six data centres into three and then two to align with geographical regions. 
Work done on Cray Supercomputers was transferred to Sun Workstations and IBM RS6000 machines" (Cross et al. 1997, p.402). The overall effect is shown in Table 1.

Table 1 BPX IT Statistics: 1989-95

\begin{tabular}{|l|l|l|l|}
\hline & $\mathbf{1 9 8 9}$ & $\mathbf{1 9 9 2}$ & $\mathbf{1 9 9 5}$ \\
\hline IT Budget & $\$ 360 \mathrm{~m}$ & $\$ 170 \mathrm{~m}$ & $\$ 132 \mathrm{~m}$ \\
\hline IT Personnel & 1400 & 390 & 150 \\
\hline IT Applications & 170 & 110 & 75 \\
\hline \%Desktop MIPS to Mainframe MIPS & $20 \%$ & $85 \%$ & $99 \%$ \\
\hline
\end{tabular}

Source: Cross et al. 1997

By 1995 it was becoming evident that BPX's IT function was not only being changed to decrease costs, improve operational efficiency and maintain the value and benefit of IT, but was expected to make an active contribution to the future business of BPX. The changes initiated by BPX formed part of a larger change agenda within BPX as a whole which increased both the complexity of the change process and the necessity of overall success (Cross et al.1997). IT outsourcing formed an integral part of this agenda as BPX now believed that it no longer needed to own the technologies that provided business information to employees. Indeed by 1995 the view was that IT services did not belong to BPX's core competencies:

"By definition more and more stuff will be outsourced in the world, there's no doubt about that. The big companies, particularly companies like ourselves that are capital intensive businesses, not a bank or financial services, information is not our stock of trade. The days of running big IT departments are over" (Head of Business Information, BPX).

Outsourcing was to be an important facilitator for this common operating environment.

The move to outsourcing In November 1991 BPX issued Requests for Information stating BPX's intention to refocus its IT department and summarising the scope of the work that would be outsourced. This was the start of a search which took 15 months to complete. The potential suppliers ranged from niche providers in areas such as data centre management, applications development, and telecommunications groups, to every major service provider in the market.

By mid 1992 a final shortlist of six service suppliers had been established. However, BPX's managers had come to realise that no single supplier could provide all their IT requirements to a best-in-class level (Currie and Willcocks 1997). Moreover, BPX's previous outsourcing experiences convinced it that although it needed different suppliers with differing skills for different activities they had to have the ability to work together. So although BPX had originally decided to selectively outsource its services it now wanted a consortium of suppliers to put forward a proposal which could meet all its IT needs through the provision of a seamless service. Only if this was possible could BPX's managers eliminate the difficulties they had previously met in maintaining a co-ordinated interface between individual suppliers. BPX recognized that the key to developing the interface between these suppliers lay in itself having good relations and hence interfaces with each of them. This was recognized to be a challenge because some of the potential suppliers were in competition with each other. 
BPX decided that the successful consortium had to consist of more than one and fewer than five companies. The challenge to the suppliers was to form a consortium to present a proposal with the best cost-performance target. The potential suppliers explored what each could do, testing their capabilities, forming alliances, dissolving them, and forming new ones. In October 1992 the proposal submitted by Sema, SAIC, and BT Syncordia was accepted by BPX as meeting all of its expectations. It was found that these three suppliers ${ }^{149}$ best complemented each others' expertise and capabilities. In addition, all of them had the capabilities to provide BPX with services globally, which was a critical competency.

Outsourcing Scope The Sema Group was contracted to operate BPX's UK data centres in Glasgow, the computer centre in Harlow, and to provide IT services for BPX's offices at Stockley Park and BPX's head office in London. SAIC was contracted to manage the IT facilities at BPX's European Headquarters and all the company's other applications. This included all the technical applications such as UNIX applications for seismic assessment. In addition, in Aberdeen it was to manage desktop and local area network services. BT Syncordia was contracted to manage BPX's telecommunications and telex networks worldwide providing data, voice and video communications services.

The contracts and arrangements BPX negotiated with the three vendors took a great deal of time to finalise and agree. Agreements were influenced by the European 'anti-trust' law, which hindered the three suppliers from formally joining in a consortium to deliver services to BPX. So BPX was forced to contract with each of the three individual suppliers, but with the implicit agreement that they had to conjointly provide the services for the variety and diversity of BPX's needs. The trio agreed to provide the seamless service that BPX desired. For each of BPX's eight major business sites - London, Aberdeen, Houston, Anchorage, Bogota, Stavanger, Stockley Park, and Sunbury-on-thames - one of the three suppliers was to serve as the primary contractor and co-ordinate the services the trio provided to most or all of the businesses supported by the site.

Outsourcing expectations and objectives BPX's management's view was that the objective of outsourcing was not only to reduce costs, but was to rebuild the whole of the IT functions and services on a different and more effective basis. It was explicitly not just swapping an outside service for an internal service. Indeed the aim was to reposition the internal IT team to create much more value rather than having them deliver IT services themselves. Overall BPX hoped to gain higher value and significant benefits from the relationship.

${ }^{149}$ The Sema Group was one of the top 5 service suppliers in Europe and its 1995 turnover was in excess of $£ 677$ million. The Group's main business areas in 1997 were consulting (13\%), systems integration (59\%), outsourcing (33\%) and IT products (8\%). Its biggest markets have been the United Kingdom and France. Science Applications International Corporation (SAIC) is based in San Diego offering a broad range of expertise in technology development and analysis, computer system development and integration, technical support services, and computer hardware and software products. SAIC has been one of the worlds largest employee owned organisations with approximately 34,000 employees in 134 cities world wide. In 1997 it achieved an annual turnover of \$3.1 billion. British Telecommunications (BT) owns Syncordia that offers global networking solutions for voice, data, video and computing. BT Syncordia had revenues of $£ 250 \mathrm{M}$ in 1996 , had $£ 1.2$ billion contract value (which implies that most of the contracts are between 3-5 years) and a headcount of approximately 1500 . 
Outsourcing was also part of BPX's strategy to restructure its IT function and to develop a common operating environment with standard packages. BPX's IT expected these suppliers to be ready and able to work with it to develop a new computing environment while continually improving the efficiency and quality of service from the old. Together with BPX's internal restructuring efforts, management expected the outsourcing arrangements would also help to diminish the costs of finding new oil fields and improve productivity.

The Aston-Clinton Principles To ensure the suppliers would work as partners with BPX, in late 1992 senior managers from SAIC, Sema, Syncordia and BPX developed the Aston Clinton Principles which encapsulated what these parties believed to be the characteristics of a successful partnering relationship:

"in terms of the intent for the relationship, all companies signed for us what was called the Aston Clinton Principles of relationships. It was something which we all wanted to adhere to, it wasn't a contract but it was the spirit in which we wanted the relationship to move forward. [...] It's the characteristics of what a partnership arrangement is. So that's about long term relationships, mutual commitment, sharing the rewards and risks, commitment to each other's success, creating win-win relationships and scenarios. Totally dependent on one another. [...] This is about working together in a way that was different." (IT Director, BPX).

These principles formed an addendum to the actual contracts agreed between all parties, but it was only a guiding framework and had no legal status. In essence the principles outlined the following:

- Simplicity of practice;

- Visibility of costs;

- Trust between the parties;

- Common understanding between the parties;

- Creation of a win-win relationship;

- Fair returns for Consortium members;

- Long-term relationship but no legal partnership between the parties;

- Site targets to be agreed locally. These targets to include the margin;

- Risk/reward arrangements to apply to the difference between the costs included within the target and the actual costs as demonstrated via an open book policy;

- Principles generally to apply on a site-by-site basis as well as on a global basis;

- From time to time, benchmarks to be established by BPX to validate "best in class" performance, not necessarily just financial performance; and

- Other alternative financial arrangements for ad-hoc activities can apply where appropriate. For examples: fixed fee or incremental cost.

In turn BPX's business managers, at each of the sixteen BPX sites, negotiated their own contracts with the IT suppliers, specifying the scope of services, service levels and performance targets. BPX agreed five-year framework agreements with Sema Group and SAIC and a two-year agreement with BT Syncordia which was later renewed in 1995 for another two years. However, in light of the high price volatility of IT services, it was BPX's intention to regularly revisit the contracts, especially for telecommunication services, and new performance contracts were negotiated annually for price rates, services and performance levels. 
The framework agreements covered generic and specific services, legal provisions, general commercial principles, financial targets, margins and incentives, quality assurance, and performance reviews. Each of the sixteen key sites then negotiated customised services with the vendor. In turn, each business unit paid for the IT services they received. Hence, suppliers directly invoiced the different sites, and the sites then had to recover their costs from the individual business units to which services were delivered. These costs were very closely scrutinised:

"The three suppliers' books are open to us; they itemise all costs clearly in quarterly or annual invoices, distinguishing among direct, allocated and corporate overhead costs charged to BPX [...]. Our agreement stipulates that we can audit our suppliers' accounts of services to us, if it proves necessary" (IT Director, BPX, quoted in Currie and Willcocks 1997, p.211).

In addition, suppliers were required to itemise all costs clearly in quarterly and annual invoices. These also had to distinguish among direct, allocated and corporate overhead costs charged to BPX. BT Syncordia was further required to present detailed records of all the telephone charges with third-party operators that BPX used worldwide.

Also included in the framework agreements were benchmarking provisions. The suppliers were required to deliver best-in-class services for specific areas. In circumstances where another provider could supply an important service more cost effectively, then BPX could insist on the relevant supplier being subcontracted and managed by the existing vendors. These arrangements ensured that BPX could always take advantage of newest technology in the market.

The start up period The start-up period was particularly difficult for all parties involved. The early days were expected to be difficult, but not to the level encountered.

"Our outsourcing strategy has not always worked smoothly; we have encountered some bumps. Indeed the first few months of the implementation were rocky" (Cross 1995, p.200).

Still, staff transfers went ahead as planned, with the majority of BPX staff being laid off during the transfer. Only $49 \%$ of the staff running BPX's services at the time were actually integrated into the three suppliers. Since BPX planned to outsource incrementally and learn by outsourcing in stages, the first country to be transitioned was the UK, which in any event had the most IT intense and diverse requirements. Early concerns arose with the negotiation of the site specific contracts and service level agreements. As the contract had been signed for all of BPX, service levels targets and price margins and other aspects still had to be localised. This was of course in accordance with the Aston Clinton Principles that all parties had agreed to prior to contracting. Not surprisingly in the first year activity frequently relapsed into merely defining and finalising agreements at each of the business sites.

This period saw a drop in service levels, as the suppliers attempted to acquire an understanding of the systems and requirements. This took quite some time and was not helped by BPX's fast changing IT strategy and structure. BPX at the time was running numerous systems and was continuing to aim to operate at the forefront of technological developments. Indeed, the suppliers found it difficult to keep up with BPX's intention to lead the market in terms of technological developments. This push effected service performance negatively and almost resulted in the failure of relations. BPX had to seriously reconsider its options in the first year and consider how to ensure suppliers could match its expectations. 
Additional problems that the vendors faced were with BPX's culture and operational structure that was still changing towards a federalist or network centric structure.

By 1995 each of BPX's eight (by 1997 it had grown to sixteen) key business sites globally had one supplier operating as the primary contractor, co-ordinating the services provided by the other suppliers. Each vendor in turn was appointed as the primary contractor somewhere, and so was ultimately responsible for a seamless service to a business site.

The service levels at each site were expressed in technical measures, such as percentage of down and up time of servers, and response time to service requests. However although by 1994, the vendors were performing according to agreed service levels, users remained dissatisfied with services. Consequently, BPX defined and implemented an important soft measure that would evaluate user levels of satisfaction. A yearly survey was distributed to key users, who were asked to rate the service performance on a scale of 1 (poor) to 5 (excellent). The minimum standard the consortium had to achieve was 3; anything below would be unsatisfactory not only for users but also for BPX in general.

Delivering services within BPX's expected cost boundary was not always easy, especially as BPX activities had spread geographically. This presented large challenges to the vendors, especially for Syncordia who had to provide the fundamental telecoms link with parts of the world that are not as technologically advanced as others.

Overseeing the outsourcing venture and consortium was the Outsourcing Management Board $(\mathrm{OMB})$, which had the following function and remit:

- Providing global/strategic direction;

- Mechanism for resolving cross site issues or issues outstanding from a site;

- One Board (BPX and all Consortium members);

- Equal voting representation for BPX and "Sema, \& Syncordia \& SAIC"; and

- Decisions will only be made on a unanimous basis unless the OMB wishes to change this arrangement (according to the Aston Clinton Principles).

Syncordia was initially only contracted for two years. In early 1995, when Syncordia was asked to re-bid for its service area, Sema and SAIC were also allowed to bid for Syncordia's business. In the end Syncordia won the bid, and was re-contracted for three years, but the process had seriously strained relations between members of the alliance.

By early 1996 all BPX sites world-wide were using outsourcing suppliers and relations in the first sites outsourced had settled down. Operationalising the consortium approach was not easy for the vendors, and relations between them had already been seriously strained by the re-bidding phase. Also disputes tended to erupt, especially between Sema and SAIC, with every placement of new business because their service portfolio and offerings were very similar in nature. However, relations between the suppliers did not break down, not least because BPX required that they did not do so, but because they had also agreed to the Aston Clinton Principles of co-operating and collaborating to provide a seamless service.

In early 1996, one of the criticisms vendors, especially the account managers, were voicing concerned BPX's management infrastructure, which had no uniform interface. Offering global services site by site meant numerous regional contracts and interface responsibilities, and these were becoming difficult to manage. Each account manager interfaced with up to 15 
people, making relationship management very difficult. BPX's IT managers were aware of this complexity but could not find a solution to this difficulty.

By having so many relations, it was difficult for managers to develop the level of rapport expected for them to be informed and up-to-date on BPX's strategic moves. Internal reports, memos, and newsletters were often the only source of information about what BPX's intentions were. The multiple interface complexity was effectively hampering communication and information exchanges, which in a number of situations resulted in unexpected surprises and pressures that drove suppliers to their limits.

However, the lack of BPX's sharing reflected BPX's perspective that its IT suppliers were commodity suppliers - even though at the outset BPX was planning to use them as valueadded providers and innovators. Yet this did not occur, certainly not with Sema and Syncordia who in practice delivered mostly process and commodity type services. Nevertheless these suppliers considered themselves to be best-in-class in their areas. Indeed although, BPX viewed SAIC as the most innovative, SAIC still found itself treated mostly as a commodity service provider, except during particular projects. At the same time BPX sought innovations from the vendors, hoping to benefit from their experiences with other clients, and from their expertise, and knowledge of technology and processes. However, innovation and value-added benefits did not evolve to the extent that BPX was expecting.

BPX's re-evaluation In the early months of 1997, BPX began to consider its future IT direction and how it would be organised. Critical to this was their outsourcing strategy, since outsourcing by then was consuming $80 \%$ of their annual IT budget and the contracts were coming to an end in March 1998. Additionally, there were a number of organisational challenges to master including the need for BPX's to devise a corporate wide common operating environment. This meant that a standard platform was required. However, it was becoming obvious that if IT commonality across the world (involving about 35,000 users) was to be achieved it was necessary to think about reducing the suppliers down to one. Such a view implied a drastic change in the existing outsourcing strategy and hence it was becoming questionable what role the consortium would then have in 1998.

An important lesson BPX had learnt over the four years of operating the outsourcing venture was that the consortium approach actually had not worked as initially planned. Even though the vendors had committed themselves to providing a seamless service through co-operation and collaboration, in many cases they found it increasingly difficult to actually work together and co-operate. Performance had suffered, forcing BPX's managers to become involved in managing the vendors more often than intended particularly in adjudicating disputes about service provisions and responsibilities, especially between Sema and SAIC. As a result BPX had had to allocate additional managers to manage the outsourcing relationships, even though one of its objectives had been to decrease the amount of time spent on the management of IT. In effect, the vendors had remained competitors, particularly in those instances where BPX placed additional business or asked for project bids.

BPX therefore decided that the consortium approach was too complicated and that it had put too much effort into managing the consortium for not much benefit. Although it had received some advantage from having multiple suppliers for particular areas, it was not felt that it was getting the benefit of economies of scale or of getting innovation from the out-source suppliers. BPX's IT model therefore no longer included the idea of procuring services 
through a consortium arrangement. A decision was made to move to another model for seamless end-to-end management.

By June 1997 BPX had defined their future IT structure and had presented their strategy to senior management and its suppliers. In terms of their outsourcing strategy it entailed one global strategic partner who would provide end-to-end service management of their infrastructure (including 35,000 desktop computers, client-servers, networks and helpdesks). Additional vendors such as Sema, SAIC and Syncordia would continue to deliver commodity services such as data centre management, application support and telecommunications. However, everything to do with the infrastructure would be single sourced.

To begin with SAIC, Sema and Syncordia were asked to bid, along with a number of other large-scale suppliers including EDS and IBM. In the end EDS was chosen as the preferred supplier and was recommended to the BPX board, which subsequently ratified the choice. In August 1998, BPX and EDS signed a five year renewable contract for the infrastructure part.

In March 1998 new contracts were also signed with Syncordia for the continued provision of telecom services world wide, with Sema to continue providing mini, midi, and mainframe legacy services, with SAIC also providing some of the former services and most of the technical application support. However, Sema and SAIC's contracts were reduced considerably, and re-contracted with EDS. In effect, most services provided by Syncordia, Sema and SAIC were commodity functions. Their operations had been clearly specified and EDS was now in charge as lead supplier for all sites globally

\section{Interpretation}

The centrality of norms in creating both the atmosphere within which relationships exist and the manner in which they operate has been recognized by many writers (e.g Heide and John 1992; Gundlach 1993; Macneil 1983). However, there are four questions regarding norms that this Case raises. These are discussed below and some tentative proposals made regarding their implications.

\section{A/ What do norms do?}

Typically "norms" are seen as creating expectations of behaviour or "norms imply a certain action and are shared by the actors" (Hakansson and Johanson 1993, p.44-5). Indeed Macneil (1983) believes that under certain conditions ${ }^{150}$ a society shares a number of common norms. These norms he believes have an impact on contractual relations because they will deem that contracts contain certain features but make it unnecessary to include statements about others. Yet the difficulty is that norms vary a great deal between and within societies. This is illustrated when formulating international contracts "when a "foreigner's" requirements as to what should go into a contract will often surprise us but what we would not consider necessary to include may surprise them.” (Blois, 1999)

It is impossible to encompass within a contract every eventuality so that there is a need for adaptability within a contract and this is well recognized within business relationships in

150 These are that there is a means of communication which both parties understand; a system of order so parties exchange instead of robbing; a monetary system; and, a mechanism to enforce promises. 
practice. The extent of this need varies between industries. It follows that, as has been commented, the efficient completion of a contract is dependent upon "workers being able to take up a lot of the uncertainty" (Stinchcombe 1990, p.236). Furthermore it is recongized that one party to a contract may change its mind about exactly what it wishes the other party to do and that this change will be accepted as long as it falls within certain limits. Such limits may not be set out within the contract in the sense of stipulating that some features can be changed at all let alone be changed only within certain limits. Indeed "Both the normal economic models of a market transaction and the legal model of a contract tend to obscure the degree to which large numbers of contracts are (realistically, though not legally) agreements to deliver an indefinite good or service for an indefinite price." (Stinchcombe 1990, p.215). Without such willingness to be adaptable many business relationships would grind rapidly and regularly to a halt. Norms are in a sense the lubricants that keep relationships from being stymied by their contractual terms.

Although norms create expectations of behaviour it is apparent in this Case that three problems arose. First, that the members of the consortium were not only expected to work closely with each other even though they were competitors but also on some sites to be the senior partner while on others to be one of the junior partners! This was a situation that was unique in their experience. There is no indication that BPX or any member of the consortium recognized in advance that the norms that they usually applied in their relationships with their clients would not therefore be applicable to this new situation. As a consequence staff at all levels were working with norms which were at best not appropriate to the new situation and at worst made for difficulties. For example, a company's norms do not normally encourage the acceptance of flexibility, information exchange and solidarity in contacts with competitors - all of which are needed if sound relationships are to be developed between organizations (Heide and Jones 1992).

The second problem was that BPX fundamentally conducted its relationship with the consortium and its individual members as if it were buying a commodity service. Yet a major reason for using outsourcing at all was BPX's desire to obtain a state of the art service in IT! Its behaviour towards the consortium was therefore based on norms that were inappropriate relative to its stated objectives.

The third problem was that one member of the consortium was not familiar with European modes of operations.

"SAIC for instance had a horrendous job trying to adapt to a non-US culture, and that was just the UK which is not too different to the US. They had a horrendous time trying to fit into the UK. They just didn't understand where people were coming from" (BPX Manager).

Thus initially the various participants in the relationship continued to apply the norms appropriate to their past experience. These arguably were almost totally inappropriate for the new structure of relationship within which they were expected to work.

It could be argued that the Aston-Clinton principles were an attempt to "create" a set of norms. Two points should be noted here. First it is questionable whether norms can be "created" in this way (see below). Second in specific situations the correct way to proceed within the spirit of the Aston-Clinton rules could only be decided within a set of norms! In other words the Aston-Clinton rules were either so vague as to be meaningless or so specific 
as to leave no room for doubt that the norm was that BPX was in charge! An example of the former being:

"The following basic principles have been agreed by BPX and the Consortium in respect of the financial/commercial framework: simplicity of practice; trust between parties; creation of a win/win relationship;....."

and of the latter:

"From time to time BPX may elect to engage a mutually agreeable third party to review the methodologies employed by Syncordia in the determination of its costs to ensure that the costs charged prior to the application of the financial framework do not include a margin"

This latter clause being included even though open-book accounting had been specified in the formal contracts!

\section{B/ How are norms formed?}

The nature of some norms can be related to fundamental cultural backgrounds but it is more difficult to identify the roots of others. For example, the links between business behaviour in S. E. Asia and "face" and "guanxi" are clear even if complex. It is also probably possible to determine through historical studies how the norms that apply between contractors within, say, the British house building industry developed. However, how norms develop when new industries or, as in this Case, new forms of organization evolve is far from apparent. This is especially a problem when, as in the case of much IT associated activity, these industries and organizational forms have evolved very rapidly and include genuinely new structures (see Bjorn-Anderson \& Turner, 1994). The importance of establishing norms is hinted at in the comment that, without them, "a buyer's ability to exercise needed vertical control is limited" (Heide and John 1992, p.42). For, even if it is not assumed that it is beneficial for buyers to have such control, this statement acts as a reminder that the lack of agreed norms has cost consequences for those involved in a relationship.

The work of Axelrod (1984) and Gronovetter (1985) is suggestive in this matter but little in the way of empirical studies seems to have been carried out. In relationships, such as the one described in the Case, which develop in a new environment presumably the relative power of the parties involved is a major factor. Thus where one organization is very dominant in a new market it seems probable that their values and approaches to business will be very influential. For example, Microsoft has, though not necessarily deliberately, exercised considerable influence over the norms which have evolved in the software market (Stinchcombe 1985).

As the Case indicates, the Aston Clinton Principles developed by senior managers from SAIC, Sema, Syncordia and BPX were an attempt to create norms to ensure that they would all work as partners. These encapsulated what these parties believed to be the characteristics of a successful partnering relationship. Although, the Aston Clinton Principles were not legally enforceable, they sought to create norms within which the contractual relations would operate. Norms under which the parties agreed to foster trustful relations, assure mutual benefits, enter into risk-reward arrangements, and provide incentives to develop and maintain relations. 
In the first year the consortium's members tried to learn to work together. It was noticeable in this period that relationships within the consortium were so poor that the whole outsourcing procedure was questioned and the arrangement nearly collapsed especially as IT service levels dropped in this period:

"BPX suffered by trying to move faster than the market could move. I think when we went to the suppliers they weren't ready to step up to where BPX wanted them to be. We got badly scorched the first 6 months of outsourcing. It then caused us to step back and we then got a real half-way house. The suppliers were then trying to step forward again and BPX was saying: 'I've been so badly burned, that's a bad place to be'. And it was at times like these that we came very close to cancelling the contracts in the first 6-9 months" (BPX Manager).

However, gradually the service levels were re-established. Yet it was still necessary for BPX to later introduce the additional 5 point soft measure that would evaluate its users' levels of satisfaction.

It seems that throughout this period the members of the consortium were learning to work with each other (i.e. developing norms) and with BPX. While at first the development of norms between the consortium members was, because they were traditionally competitors, slow and difficult gradually a workable structure began to develop. Furthermore, relationships between the individual consortium members and BPX remained "frosty" as most of BPX's managers perception was that this was a commodity outsourcing deal. Consequently they fundamentally viewed it as a transactional exchange rather than a relationship. BPX then disrupted the development process by encouraging two of the three members of the consortium to bid against the third for the renewal of its contract.

A further problem with the development of norms was a consequence of BPX's view that it was buying a commodity and a specific example of the consequences of this was BPX's failure to share information with its suppliers. This not only meant that BPX could not obtain the benefits that it had wanted from the process of outsourcing but also the relationship between the consortium members was strained to breaking point.

Commons (1950), while accepting that they overlap, suggested that transactions are dynamic and go through three temporal stages: negotiation; agreement; and, execution. It is in the agreement stage that the governance structures plus the structural and procedural safeguards are set up which will organize the deal. In the execution stage, if those already set up prove to be inadequate, renegotiation and adaptation of these structures and safeguards may be required. The difficulty in this Case was that the members of the consortium needed to go through these stages to establish relationships with each other (a complicated process because of their traditional posture being one of competition rather than co-operation) while almost simultaneously, but acting as a consortium, they went through these three stages with BPX!

BPX expected to move from sending the initial Requests for Information to potential suppliers to implementing the first outsourced arrangements in about 15 months. This would have been a challenge if it was a normal outsourcing arrangement but between issuing the Requests for Information and letting the contract, BPX changed the nature of their demands to require outsourcers to form consortia! In retrospect it is not entirely surprising that problems arose with such rapid change not least because personal relationships can contribute a great deal to the establishment and maintenance of agreed norms. As Ring and Van de Ven (1994, p.109) state "if personal relationships do not supplement formal relationship over 
time, then the likelihood increases that conflicts will escalate" and personal relationships take time to develop.

\section{C/ How do norms operate within complex relationships?}

It has commonly been observed that in business relationships that the nature of exchanges that occur between the personnel involved in the participating organizations can vary a great deal. Thus senior staff may react with each other in a quite different manner than junior staff. Sometimes the relationships at a senior level are more relaxed than those at a junior level. Yet the opposite can also be true with junior staff making the relationship work on a day to day level in spite of adversarial behaviour between the directors.

Sometimes staff roles also seem to strongly influence the nature of the interactions that occur (Green, 1995). Here sometimes the common language and values of professions or crafts are more important than the organizations' view of the relationship. So, say, two accountants will be able to sort out a dispute between their firms when a lawyer from one firm and an accountant from the other could not. This both because they are two professionals with the same training but also because of some sense of professional solidarity. Indeed it has been asserted that "More efficacious negotiation appears to result when the counterpart architects of negotiating strategy between two organizations play the same roles (that is, manager and managers or lawyers and lawyers)." (Ring and Van de Ven 1989, p.186)

The above would suggest both that not only may there be a hierarchy of norms which apply to a relationship but also that norms are multidimensional (Hiede \& John; Noordewier et al.). Thus there will be an over-arching set of norms within which those individuals whose job it is to operationalise the relationship have to function. They may however consciously operate with different norms. For example a salesperson and a buyer may work closely together freely "bending the rules" to keep the relationship working smoothly at a day to day level even though the norm imposed by their separate organizations is that everything should be "done by the book" and that the relationship should be strictly formal. Of course the opposite could be the case and the relationship between specific individuals could be difficult in spite of the organizations' declared intent to build a close relationship. Both Guitot (1977) and Gabarro (I987) point out that, within a newly formed organizational relationship, individuals' relationships will at first be determined by their role. Over time, though their role will not disappear, it may merely diminish in favour of the "qua persona" (Guitot, 1977). However, the nature of exchange, even within a role, is strongly influenced by the personality of those involved (Zaheer et al. 1998).

The structure of the consortium and its relationships with BPX were very complex. Overseeing the outsourcing venture was the Outsourcing Management Board that was composed of senior managers from BPX and the consortium. The vendors' account managers held ultimate control over the relationship on behalf of the consortium both on a global, and also regional level. Their responsibility was to oversee site performance, new business opportunities and resolve any major problems. The account managers however had little impact on day-to-day interactions. The vendors line or relationship managers were responsible for overseeing service performance regionally and interfaced with BPX's regional partner resource manager and business information managers. It seems that while at the higher levels relationships were good at the operational level they were mostly adversarial. There are many possible reasons for this discrepancy of approach but it is possible that the rapid setting up the arrangement had left too little time for senior 
management in BPX and the consortia to communicate effectively with their operational managers.

In early 1996, the account managers were voicing concern about BPX's management infrastructure, which had no uniform interface:

"there's no one single point of accountability in BPX [...]. They are very difficult to deal with because they present so many different faces. And what that means is that a company trying to deal and provide a consistent service has got a whole load of people to satisfy and that makes it very difficult to get an agreement across all those people because they've all got slightly different agendas and requirements. So that's the problem we've got, the hardest part I would say" (Senior Contract Manager, Syncordia).

Interestingly, BPX's was aware of this complexity.

"So they are now beginning to build up lots of little contracts and also they began to get involved with Sunbury as well. So now all of a sudden they've got 7 or 8 different contracts in the South East and BPX doesn't talk to them in the same way. And this is the issue about the many different faces of BPX. Their interfaces are making different demands of them and they couldn't view BPX as a whole" (Relationship Manager, BPX).

So numerous people of differing levels of seniority, professional and cultural backgrounds, and, experience were all interacting with each other. Each was bringing their own experiences; demands of their role; and, expectations to the relationships and not surprisingly the result, because there were no established norms, was confusion.

\section{D/ How can norms be classified?}

Many classifications of norms have been proposed but there is no one that is regarded as dominant. Macneil's ten norms (1983) are very influential though, perhaps because of the substantial difficulty in operationalising them, they have been less used than might be expected. Other writers (e.g. Kaufman and Stern 1988) have produced modified versions of Macneil's norms. Heide and John (1992), working from Macneil's norms, propose that relational norms are a higher order construct consisting of the three dimensions:

flexibility which defines a bilateral expectation of willingness to make adaptations as circumstances change;

information exchange which defines a bilateral expectation that parties will proactively provide information useful to the partner; and,

solidarity which defines a bilateral expectation that a high value is placed on the relationship. It prescribes behaviours directed specifically toward relationship maintenance.

Of these only flexibility is evident as being displayed by the members of the consortium and $\mathrm{BPX}$ recognized this describing, for example, SAIC as follows:

"But I would say they are the ones that have worked the hardest to develop a relationship with BPX and to be flexible in respect of not worrying too much about the contract but thinking about how they can change the processes or structures to suit our needs." (Deputy Head of IT, BPX). 
However such flexibility did not seem, on its own admission, to be reciprocated by BPX:

"One criticism which is legitimate from all the outsource companies is we are pretty bad at presenting a uniform face to them" (Relationship Manager, BPX).

There is in contrast clear evidence of BPX's failure to accept that information exchange with members of the consortium was important. As one SEMA manager complained:

"So I have seen their strategy at the beginning of 9 months now I've seen, not once where BPX sits down, not even once a week, once a month or once every six months, it does not sit down with the suppliers and says 'this is where we are trying to get to'. You can read it in the company newsletters, you can find things out and I'm finding out what they are doing in Algeria at the moment for example, but I've not seen any evidence where BPX sits down and shares with its suppliers" (Account Manager, Sema).

As for solidarity, BPX's encouragement of Sema and SAIC to submit bids against Syncordia and implicitly against each other was action guaranteed to create distrust between the members of the consortium. It also provided evidence to the members of the consortium that BPX had little long-term commitment to them individually. Indeed it signalled that BPX would always be willing to seek out alternative suppliers if only as a method of keeping the consortium members on their toes.

There was also a tendency for BPX to imply that the difficulties in the relationship had mostly arisen from the behaviour of the consortium:

"Now you have to be careful because the danger is that each of them [suppliers] blames the other for a problem and things fall down between them. So it's not so straightforward. The experience is though that if you try and get people to work together where they are both basically doing the same thing, [...] it is difficult to manage and to develop the inter-link" (Commercial Manager, BPX).

Certainly if the presence of flexibility, information exchange and solidarity is necessary if relational norms are to operate then it is not surprising that this complex relationship effectively failed.

\section{E/ Some implications}

It is often suggested that an identifiable characteristic of a close business to business relationship is the willingness of both parties to adapt. However, much of the literature at least implies that adaptation involves investment in tangible facilities. For example "Adaptations presume investments that may partially lead to relationship-specific assets" (Moller and Wilson 1995, p.42). However, what appears to be important in this Case is the need for adaptation with regard to intangible features such as "norms".

In more typical buyer supplier relationships (such as for example the relationship that BPX developed with EDS in 1998 which was a normal outsourcing arrangement under which all parties understood their roles) there is less need to worry about adaptation of norms. However, when a new form of organizational inter-relationship is being created then it cannot be presumed that the existing norms will be effective. Having talked "partnership" BPX effectively subcontracted a major problem to the consortium members assuming that the members of the consortium would sort out their new inter-relationships. Furthermore, 
although it was talking partnership, BPX made it clear that it was in charge of the overall relationship between the consortium and itself. BPX seemed to have initially allocated no managerial time to assisting the members of the consortium to establish new norms of behaviour towards each other appropriate to their new roles as collaborators - although remaining as competitors outside of this context. In addition BPX did not internally clarify what the objectives of the exercise were with some of its managers seeing it only as a commodity supply arrangement rather than a partnership ensuring BPX's access to leading edge developments. What is worse just as norms were evolving BPX "reminded" them that they were still fundamentally competitors by inviting them to bid against each other!

Selznick (1957) has argued that a relationship does not become institutionalized until norms and values have been established with enough clarity for the relationship to be able to continue beyond the immediate tenure of its founders. Such a process must take time yet BPX moved to implement these new outsourcing arrangements in a very short period of time (arguably very short even for a more traditional outsourcing arrangement). Although commentators recognize that negotiation; agreement; and, execution - the three stages of a transaction - may overlap it is not generally recommended that any two of them are conducted almost simultaneously. In fact BPX's timetable left little room for anything but discussion of technical matters.

The timetable also seems to have failed to recognize "that underlying formal contracts are a host of backstage interpersonal dynamics that mobilize and direct the formal contracting process but are seldom visible or explicitly written into the formal contract" (Ring and Van der Ven 1989, p.179). Neither does BPX seem to have understood the "the tension produced by inherently contradictory roles enacted by transacting individuals." (Ring and Van der Ven 1989, p.172) whereby an individual needs to reconcile their personal interests with those of the organization. Such reconciliation takes time.

Finally, if the consortium was to be a success then its members would have had to show flexibility, information exchange and solidarity towards each other. However, BPX's conduct made it unlikely that they would behave in this way. Particularly damaging, as has been pointed out, was BPX's decision to encourage them to compete against each other but not much less serious was BPX's inclination to treat them as commodity suppliers. Commodity suppliers after all do not make profits by being flexible or showing solidarity towards each other or by exchanging information.

In summary the Case suggests that:

A/ where an unusual organizational structure is proposed management must recognize the possibility that the norms dominant within the constituent organizations will not necessarily be compatible.

B/ where the norms are not compatible then action must be taken through change management schemes to develop appropriate norms; and,

$\mathrm{C} /$ the development and internalisation of new norms takes time. 


\section{Concluding comments}

This case exemplified total IT outsourcing through the use of multiple suppliers working together as a consortium. The approach taken gave BPX the benefits of selective outsourcing, avoiding the potential danger of contractual lock-in as is often the case in total outsourcing (Kern \& Willcocks, 2000). Influenced by its previous experience with facilities management arrangement in the 1980s, which had highlighted the difficulties of obtaining value and true benefits, BPX decide that if they were again to outsource they would actively pursue partnering based relations that integrate risk-reward sharing arrangements to attain real value. In addition, the sheer size of BPX's undertaking and the resulting requirements led it to consider using more than just one supplier partner and to try using a consortium based partner arrangement (Currie and Willcocks 1997).

BPX started its outsourcing venture from a strong position. It entered outsourcing with a very lean and operationally efficient organisation, where many of the usual overheads found in large organisations had already been reduced. It had also gained invaluable knowledge from its prior experience of outsourcing.

The downside of the consortium outsourcing arrangement was the increase in transaction or management costs of simultaneously handling three and more suppliers. BPX made early efforts to transfer the management responsibility to the consortium by appointing a lead contractor for each site and compelling them to deliver a seamless service for all areas contracted. Yet on many occasions ongoing competitiveness between vendors demanded adjudication and hence active BPX management involvement. When such co-ordination problems arose, the responsibility for any problems was passed between the suppliers resulting in a 'finger pointing match', with nobody taking the blame in the end for poor service performance (Currie and Willcocks 1997). The aftermath of these disputes about service competencies diminished the sharing of both resources and commercial knowledge.

"When you look at outsourcing in hindsight we find that almost everywhere we rarely meet any cost saving targets for outsourcing, it almost always costs us at least as much money, if not more. On some kind of per-unit basis when you can measure it, it is always hard to do. So our conclusions recently have been that alliances don't work. You don't assemble a group of vendors and say be nice boys and go of and do good things for us. It just hasn't taken off at all. There's got to be a prime contract or somebody among the contractors has got to step forward and say I'm going to be the lead contractor. People just don't co-operate out of altruistic behaviours and so on. We rarely save the money we had hoped to save." (Head of Business Information and Process International Systems Programmme, BP).

Many factors led to this being a less than successful experiment in outsourcing. However a major contributor was a failure to recognize in advance that there would be a need to establish norms of behaviour appropriate to this form of organization. However given that the four questions

What do norms do? How are norms formed? How do norms operate within complex relationships? How can norms be classified?

remain, as yet, at least partially unanswered this is not a criticism of the participants but a challenge to researchers. Certainly after its experiences BPX reverted to a more traditional buyer-supplier relationship leaving EDS to supply its IT by managing, on a hierarchical basis, a group of suppliers. 


\section{References}

Axelrod, R. (1984), The evolution of cooperation, New York: Basic Books.

Benbasat, I., D.K. Goldstein and M. Mead (1987), "The case research strategy in studies in information management," MIS Quarterly, (September), 369-386.

Bjorn-Andersen, N. and J. A. Turner (1994). "Creating the Twenty-First Century Organization: The Metamorphosis of Oticon", in R. Baskerville, S. Smithson, O. Ngwenyama and J. I. DeGross (Ed.), Transforming Organizations with Information Technology., NorthHolland, Elsevier Sceince B.V.: 379-394.

Blois, K.J. (1999), “A Framework for Assessing Relationships" $28^{\text {th }}$. Annual Conference of the European Marketing Academy, Hummboldt Universitat, Berlin

Commons, J.R. (1950), The Economics of Collective Actions, Madison: University of Wisconsin Press.

Cross, J., (1995), "IT Outsourcing: British Petroleum's Competitive Approach," Harvard Business Review, (May-June), 94-102

Cross, J., M.J. Earl and J.L. Sampler, (1997), "The Transformation of the IT Function at British Petroleum," MIS Quarterly, 21:4, 401-423.

Currie, W.L. and L. Willcocks, (1997), New Strategies in IT Outsourcing, London: Business Intelligence Ltd.

Gabarro, J.J. (1987), “The Development of Working Relationships," 172-189 in J.W. Lorsch (ed.) The Handbook of Organizational Behaviour, Englewood Cliffs, New Jersey: PrenticeHall Inc.

Green, R.L. (1995) 'Partnering and Alliances: Theory and Practice', Offshore Europe Conference, Aberdeen, $5^{\text {th }} .8^{\text {th }}$. September.

Gronovetter, M. (1985), "Economic Action and Social Structure: The Problem of Embeddedness," American Sociological Review, 91, 481-510.

Guitot, J.M. (1977), "Attribution and Identity Construction: Some comments," American Sociological Review, 42, 692-704.

Gundlach, G.T. "Governance in Exchange: Contract law and its alternatives," Journal of Public Policy and Marketing, 12:2, 141-156.

Hakansson, H. and J. Johanson, (1993), "The network as a governance structure," 35-51 in G. Grabher (ed.), The embedded firm, London: Routeledge

Heide, J.B. and G. Jones, (1992), "Do Norms Matter in Marketing Relationships?" Journal of Marketing, 56(April), 32-44. 
Jones, G. (1991) "British Petroleum Company Plc", in Hast, A. (Ed.) International Directory of Company Histories, Vol. 4, St. James Press, Chicago, pp. 378-380.

Kaufman, P.J. and L.W. Stern, (1988), "Relational Conflict Norms, Perceptions of Unfairness, and Retained Hostility in Commercial Litigation," Journal of Conflict Resolution, 32 (September), 534-552.

Kern, T. and L.P. Willcocks (2000), "The Relationship Advantage: Technologies, Sourcing and Management", Oxford University Press, Forthcoming.

Lacity, M. C. and R. Hirschheim (1993). Information Systems Outsourcing: Myths, Metaphors and Realities. Chichester, John Wiley \& Sons Ltd.

Loh, L. and N. Venkatraman (1992). "Diffusion of Information Technology Outsourcing: Influence Sources and the Kodak Effect." Information Systems Research 4(3): 334-358.

Macneil, I.R. (1983). "Values in Contract: internal and external", Northwestern University Law Review, 78:2, 340-418.

Moller, K. and D. Wilson, (1995) "Business Relationships - Interaction Perspective," 23-52 in K. Moller and D. Wilson (eds.), Business Marketing: An Interaction and Network Perspective, Boston: Kluwer Academic Publishers.

Mortished, C. (1998) “Corporate Profile: BP”, The Times, Business News, June 29, p. 44.

Pettigrew, A.M. (1990), "Context and Action in the Transformation of the Firm," Journal of Management Studies, 24 (6), 649-670.

Ring. P.S. and A.H. Van de Ven, (1989), "Formal and Informal Dimensions of Transactions" in Research on the Management of Innovation, A.H. Van der Ven et al., eds. New York: Harper \& Row Inc.

Ring. P.S. and A.H. Van de Ven, (1994), "Developmental Processes of Cooperative Interorganizational Relationships," Academy of Management Review, 19:1, 90-118.

Sanders, P. (1982), "Phenomenology: A New Way of Viewing Organizational Research," Academy of Management Review, 7:3, 63-79.

Selznick, P. (1957), Leadership in Administration, New York: Harper \& Row.

Stinchcombe, A.L. (1985), "Contracts as Hierarchical Documents" 121-171 in A.L. Stinchcombe and C. Heimer (eds.), Organizational Theory and Project Management, Oslo: Norwegian University Press.

Stinchcombe, A.L. (1990), Information and Organizations, Berkeley: University of California Press.

Walsham, G. (1993), Interpreting Information Systems in Organizations, Chichester: John Wiley \& Sons. 
Zaheer, A., B. McEvily and V. Peronne, (1998), "Does Trust Matter? Exploring the Effects of Interorganizational and Interpersonal Trust on Performance", Organizational Science, 9:2, 141-159. 